\title{
2323. Prediction of long-term creep deflection of seismic isolation bearings
}

\author{
Ju Oh${ }^{1}$, Jin Ho Kim² \\ ${ }^{1}$ Korean Intellectual Property Office, Daejeon, Korea \\ ${ }^{2}$ Department of Mechanical Engineering, Yeungnam University, Gyeongsan, Gyeongbuk, Korea \\ ${ }^{2}$ Corresponding author \\ E-mail: ${ }^{1}$ oju1030@daum.net, ${ }^{2}$ jinhokim0816@gmail.com
}

Received 3 September 2016; received in revised form 10 October 2016; accepted 22 October 2016 DOI https://doi.org/10.21595/jve.2016.16798

Check for updates

\begin{abstract}
Isolation structures use high damping rubber bearings (HDRBs), lead rubber bearings (LRBs), and natural rubber bearings (NRBs) in order to significantly reduce the seismic forces transmitted from a substructure to a superstructure. The laminated rubber bearing is the most important structural member of a seismic isolation system. We present an analysis of a $1000 \mathrm{hr}$ ongoing creep test conducted at 7.5 and $8.37 \mathrm{MPa}$ in our laboratory. The long term behavior of bridge bearings (e.g., laminated rubber bearings) is determined through compression creep tests subjected to actual environmental conditions. These tests indicate that the maximum creep deformation is about 0.3 to $1.92 \%$ of the total rubber thickness.
\end{abstract}

Keywords: seismic isolation system, high-damping rubber bearing, creep, long-term deformation.

\section{Introduction}

A bridge bearing system must perform two functions: one is to resist vertical applied loads and deliver the loads to the substructure, and the other is to resist horizontal forces and displacements of the substructure and superstructure $[1,2]$. These two functions are critical factors that are directly related to the horizontality of the bridge structure. In consideration of the durability of a laminated rubber bearing, the long term creep deformation made by rubber layers aging by oxidization and by axis compressive stress over the long term is very important [3]. However, in actual practice, it is hard to determine the necessary data, since creep deformation is influenced by the loading time of the bridge's upper structure and the temperature conditions [4]. Thus, the vertical deformation due to long term creep of a lead rubber bearing (LRB) is usually not considered during the design. Generally, the performance of a seismic isolation system such as a laminated rubber bearing is characterized by special tests such as a compressive test or compressive shear test on the material used in the bearing.

According to previous studies, creep tests have been performed on rubber test specimens which separated into chloroprene (CR) and natural rubber (NR) [5, 6]. However, the properties of a specimen's rubber material can be analogized but cannot be defined as the estimation of the laminated rubber bearing. C. J. Deham and R. A. Waller have estimated 100 years of bearing life after creep deformation of a laminated rubber bearing designed to isolate buildings from subway vibration by measuring its deformation changes for 15 years [7]. However, this approach is not effective since it takes too much time to estimate the results by measuring data.

In the present research, a creep test was performed on three types of laminated rubber bearings such as high damping rubber bearings (HDRBs), lead rubber bearings (LRBs), and natural rubber bearing (NRBs) for $100 \mathrm{hr}$. The test result was used to analyze the creep properties of laminated rubber bearing. Also, we forecast the durable span of a structure after 60 and $100 \mathrm{yr}$ of use [8]. It is necessary to clearly identify the properties of creep of a laminated rubber bearing under the high compression stress conditions of a real seismic isolation structure. In this regard, we estimated and analyzed long term deformation through creep tests according to the types of axis stress and laminated rubber bearings. After measuring the rubber's expansion and compression with respect to temperature changes, the test results show that the amount of creep will not exceed $10 \%$ of the total rubber thickness after 100 years of use. 


\section{Test specimens}

The HDRBs, LRBs, and NRBs used in the tests are seismic isolation system components, and are designed to match the dynamic characteristics of bridges and buildings. They are laminated with rubber and armature plates. The LRB has a lead plug installed in the center of specimen [9]. The HDRN and LRB dissipate energy in each cycle (EDC), but NRB has relatively EDC than above two specimens. The specimens used in the creep test and fatigue test are designed to satisfy various conditions: a serviceability limit state with respect to a design compression force, resistance against wind loads, and an ultimate limit state due to an earthquake. The specimens used in this research were manufactured as standard specimens per ISO 22762 [10]. The section shape and composition are shown in Fig. 1.

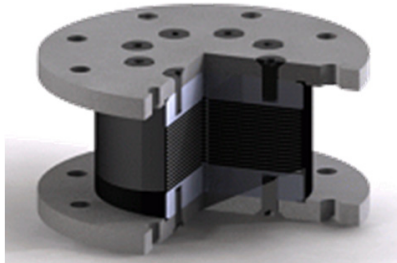

a) HDRB

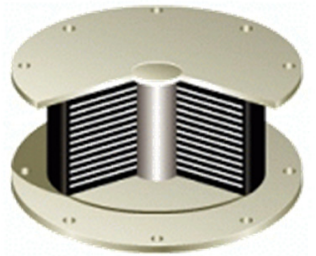

b) LRB

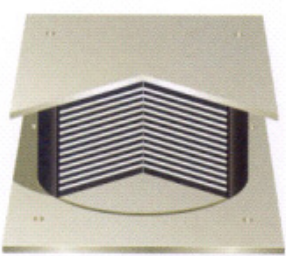

c) NRB

Fig. 1. Inside section shapes of test specimens

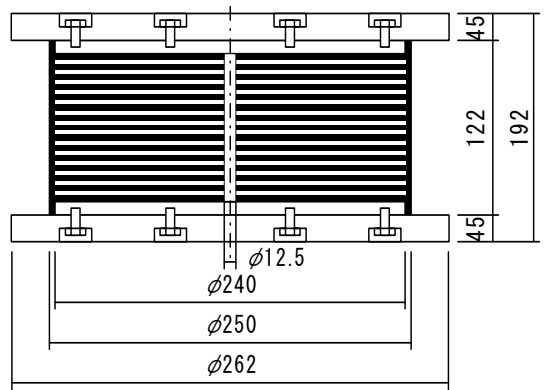

a) $\operatorname{HDRB}($ No. 1, 2, and 3)

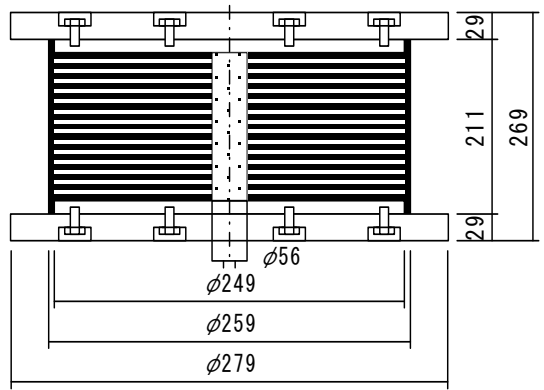

b) LRB (No. 4)

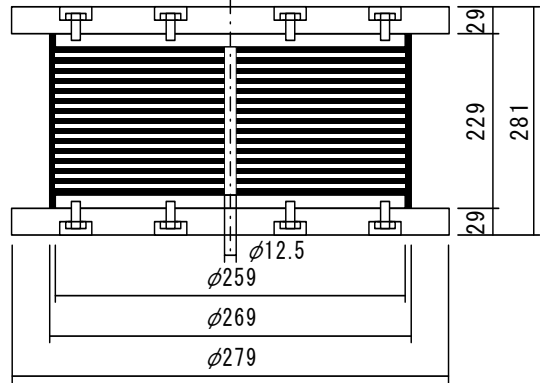

c) NRB (No. 5)

Fig. 2. Specimen types

The specification and structure of test specimens are shown in Table 1 and Fig. 2. There is a difference in the size of the specimens, but their main material composition is natural rubber. As shown in Fig. 3, specimens No. 1, No. 2, and No. 3 are HDRBs that have a damping to the rubber itself. No. 4 is an LRB, which has lead insuled inside of a rubber bearing. Specimen No. 5. is a general NRB. The specimen's diameter includes an outside rubber thickness of $10 \mathrm{~mm}$, with inner layer laminated rubber thicknesses of 2 and $3 \mathrm{~mm}$, and an inner laminated plate layer thickness of $3 \mathrm{~mm} . S_{1}$ is the primary shape factor (the ratio of the load square to the free surface square, 
including one hole inside the rubber layer) [11]. $S_{2}$ is the secondary shape factor, which represents the effective width ratio versus the total thickness of the inner rubber layer [12]. Each shape factor was calculated as follows:

$S_{1}=\left(\frac{D_{s}-D_{h}}{4 t_{i}}\right), \quad S_{2}=\left(\frac{D_{s}}{n t_{i}}\right)$

where $D_{s}$ is the diameter of the inner plate, $D_{h}$ is the diameter of the inner hole, $t_{i}$ is the thickness of a rubber layer, and $n$ is the number of rubber layers.

Table 1. Specification of laminated rubber bearing

\begin{tabular}{|c|c|c|c|c|c|c|c|}
\hline Specimen & $\begin{array}{c}\text { Diameter } \\
(\mathrm{mm})\end{array}$ & $\begin{array}{c}\text { Rubber thickness } \\
(\mathrm{mm})\end{array}$ & $\begin{array}{c}\text { Number of } \\
\text { layers }\end{array}$ & $S_{1}$ & $S_{2}$ & $\begin{array}{c}\text { Axial stress } \\
(\mathrm{MPa})\end{array}$ & $\begin{array}{c}\text { Shear modulus } \\
(G)(\mathrm{GPa})\end{array}$ \\
\hline No.1 & 250 & 2 & 25 & 29.7 & 5 & 7.5 & 0.8 \\
\hline No. 2 & 250 & 2 & 25 & 29.7 & 5 & 7.5 & 0.8 \\
\hline No. 3 & 250 & 2 & 25 & 29.7 & 5 & 7.5 & 0.4 \\
\hline No. 4 & 259 & 3 & 29 & 21.6 & 3 & 10.8 & 0.4 \\
\hline No. 5 & 269 & 3 & 31 & 16.6 & 2.8 & 8.4 & 0.4 \\
\hline
\end{tabular}

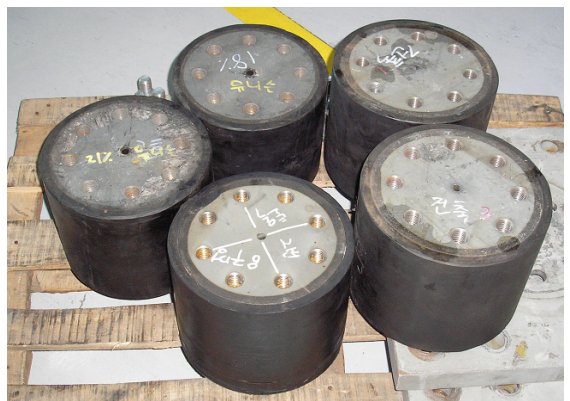

Fig. 3. Creep and fatigue test specimens

\section{Test specimens}

Fig. 4 A fatigue testing machine was used to perform the creep test on the laminated rubber bearings. The force displacement of the testing machine is a horizontal displacement of $\pm 200 \mathrm{~mm}$ and the available vertical load is $\pm 2000 \mathrm{kN}$. Deviation of the compressive load is less than $3 \%$. The specifications of testing machine are given in Table 2.

Table 2. Fatigue tester specifications

\begin{tabular}{|c|c|c|c|}
\hline & Max. load (kN) & Max. stroke & Max. speed \\
\hline Vertical & \pm 2000 & $\pm 100 \mathrm{~mm}$ & $100 \mathrm{~mm} / \mathrm{s}$ \\
\hline Horizontal & \pm 500 & $\pm 200 \mathrm{~mm}$ & $250 \mathrm{~mm} / \mathrm{s}$ \\
\hline
\end{tabular}

The latest performance test standard for laminated rubber bearings is ISO 22762 (Elastomeric Seismic-protection Isolations). ISO 22762 describes an LRB in a seismic isolation system used for protecting a bridge or building from earthquake damage in three parts. Part 1 describes the test procedure for the laminated rubber bearing $[13,14]$. Part 2 describes the design standards $[15,16]$. Part 3 describes product inspection standards $[17,18]$. In this study, we fabricated the specimens and executed the tests according to ISO 22762 Part 1. In addition, we executed the creep test using same specimen after performing dependence tests including compression properties and shear properties, as defined by ISO 22762 . 


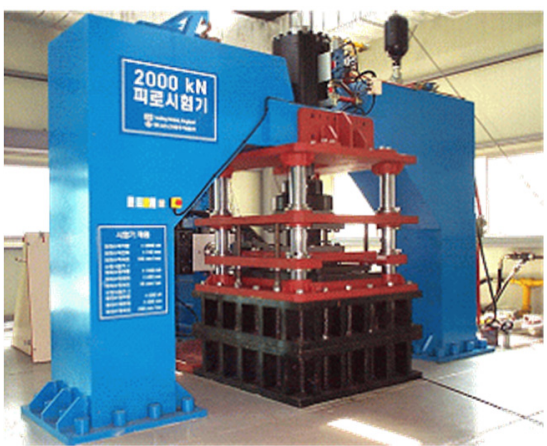

Fig. 4. Fatigue testing machine

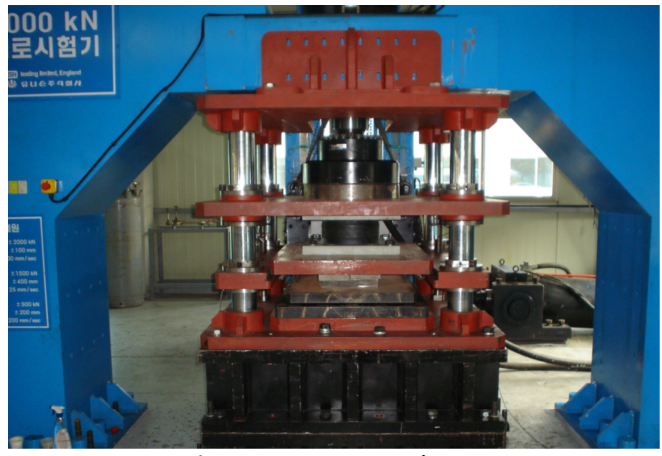

Fig. 5. Creep experiment

The creep test is performed to determine the deformation of a laminated rubber bearing under constant long term compression without shear train. The creep was measured at 10 more points of specimen during three cases of periods such as $10^{0} \mathrm{hr}$ to $10^{1} \mathrm{hr}, 10^{1} \mathrm{hr}$ to $10^{2} \mathrm{hr}$ and $10^{2} \mathrm{hr}$ to $10^{3}$ hr.

Specimen No. 1 was tested under $23{ }^{\circ} \mathrm{C}$ temperature conditions, and the other two specimens were tested under a constant temperature of $23 \pm 2{ }^{\circ} \mathrm{C}$ to determine the long term deformation of a laminated rubber bearing versus temperature. The vertical displacement of the specimen was measured by installing two highly sensitive displacement devices and the vertical displacement was determined by the mean of two measured values. The test conditions are shown in Fig. 5. The vertical load was a compressive stress applied for $1 \mathrm{~min}$. The compression force loads applied to the specimens were as follows: Nos. 1, 2, and 3 were $370 \mathrm{kN}$ each, No. 4 was $580 \mathrm{kN}$, and No. 5 was $450 \mathrm{kN}$. The deviation of the compressive load was less than $3 \%$.

\section{Test specimens}

Fig. 6 shows the change in vertical displacement immediately after applying the compressive load during the temperature change condition. This vertical displacement is the relative displacement with respect to the vertical displacement against the LRB, and would decrease with expansion of the laminated rubber.

Specimen No. 1 was tested at $23{ }^{\circ} \mathrm{C}$. Under the temperature changing condition, it is necessary to convert the temperature to compare the displacement of specimen No. 1 with another specimen that was tested under a constant temperature of $23 \pm 2{ }^{\circ} \mathrm{C}$ [19]. The relation of vertical displacement at $23{ }^{\circ} \mathrm{C}$ with $\Delta H_{T}$ is the change in the vertical displacement at $T{ }^{\circ} \mathrm{C}$ are as follows:

$\Delta H_{23}=\Delta H_{T}+n t_{r}(T-23) \alpha$,

where $\Delta H_{23}$ means the change in the vertical displacement at $23{ }^{\circ} \mathrm{C}$, and $\Delta H_{T}$ is the change in the vertical displacement at $T{ }^{\circ} \mathrm{C}$. $T$ is the surface temperature $\left({ }^{\circ} \mathrm{C}\right)$ of the test specimen, and $\alpha$ is the coefficient of linear thermal expansion $\left(23^{\circ} \mathrm{C}\right.$ at $\left.T^{\circ} \mathrm{C}\right)$.

The coefficient of thermal expansion of specimen No. 1 at each time interval is given in Table 3. The creep deformation rate is calculated as follows:

$\varepsilon_{c r}=\frac{\Delta H_{23}}{n t_{r}} \times 100$

The coefficients $a$ and $b$ of the functional equation given by Eq. (4) can be calculated by the creep deformation of specimen Nos. 2 to 5 (with test temperatures constantly maintained at $23 \pm 2{ }^{\circ} \mathrm{C}$. The result is substituted into Eq. (5) [20]. Here, $\varepsilon_{c r}$ is the percentage of total rubber thickness with respect to the creep amount after decades of use, and $t$ is the time in hours: 
$\log _{10} \varepsilon_{c r}=\log _{10} a+b \log _{10} t$

$\varepsilon_{c r}=a t^{b}$.

Table 3. Thermal coefficient $\alpha\left(\mathrm{mm} /{ }^{\circ} \mathrm{C}\right)$

\begin{tabular}{|c|c|c|}
\hline Time & 1 to $100 \mathrm{hr}$ & 101 to $1000 \mathrm{hr}$ \\
\hline Linear gradient & -0.000371094 & -0.000329716 \\
\hline
\end{tabular}

We measured the vertical displacement with a loading design compressive load for $1000 \mathrm{hr}$ under different conditions using three types of laminated rubber bearings. The test results show that specimen No. 1 tested at air temperature has 2.7 times and 3.9 times the vertical deformation of specimen Nos. 2 and 3, respectively, when tested under constant temperature. No. 3 (the high damping rubber bearing) had the smallest vertical deformation. Fig. 6 shows the test results for each specimen for $1000 \mathrm{hr}$.

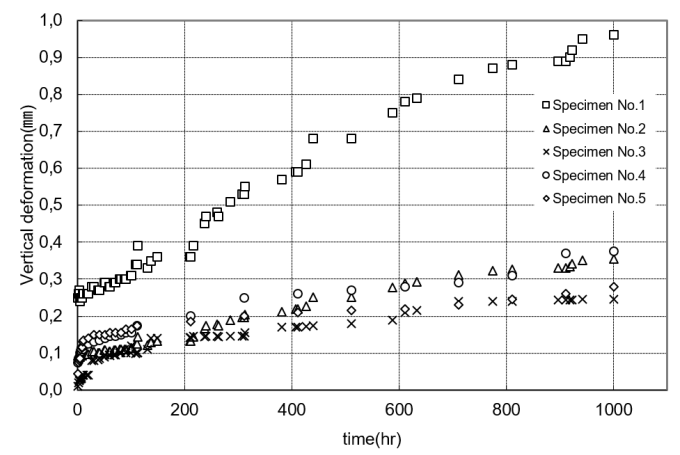

Fig. 6. Changes in vertical deformation versus time

Fig. 7 shows the change in vertical displacement versus test temperature after applying the design compressive load. Specimen No. 1 was tested under ${ }^{\circ} \mathrm{C}$ and shows a sharp increase in vertical deformation as the temperature decreased. On the other hand, specimen No. 2 was tested under a constant temperature of $23 \pm 2{ }^{\circ} \mathrm{C}$ and shows a relatively stable and gradual increase in vertical deformation. The vertical displacement also shows repeated compression and expansion of the rubber with temperature changes. Fig. 8 shows the vertical deformation versus temperature change. The lower the temperature, the higher the vertical displacement, and with higher temperature, the vertical displacement decreases. Figs. 9 and 10 show the mutual relationship between the shear modulus $(G)$ and primary shape factor $\left(S_{1}\right)$. If the section property and the shape factor are the same, an increase in shear modulus produces an increase in the amount of creep. Also, with an increase in the primary shape factor $\left(S_{1}\right)$, the vertical rigidity increases and the creep amount decreases. Specimen No. 4 in Fig. 10 has a lead plug in the central laminated rubber. In this case, the creep amount and the shape factor $\left(S_{1}\right)$ increaseafter $100 \mathrm{hrs}$. Compared with the same size specimen (No. 5), the axis compressive stress is large, but the area receiving compressive load decreases due to the lead plug inside. Thus, its vertical deformation increases after a certain amount of time.

Table 4 shows a semi-logarthmic time axis of creep after 60 and 100 years of use according to Eq. (5). We estimated that the amount of creep in a high damping rubber bearing (Nos. 1, 2, and 3) under compressive stress of $7.5 \mathrm{MPa}$ after $100 \mathrm{yr}$ to be 0.56 to $2.92 \mathrm{~mm}$. We also estimated that the lead rubber bearing (No. 4) creep amount is $1.16 \mathrm{~mm}$ and the compressive stress rubber bearing is $1.08 \mathrm{~mm}$. According to Oh et al., rubber creep visually occurs as many years pass, it decreases as the primary shape factor $\left(S_{1}\right)$ increases, and it depends on the value of $S_{1}$ regardless of the axis stress. If this is correct, the creep test on the laminated rubber bearing should be performed over a much longer period, and should be studied through long term creep test by converting shape factor. Table 4 shows the creep data and its rate of change after 60 yrs and 100 yrs of use by using vertical 
displacement data of the laminated rubber bearing after a loading design compression load was applied for $1000 \mathrm{hrs}$. The long-term creep estimate was calculated as the semi-logarithmic according to Eqs. (4) and (5), as shown in Fig. 11.

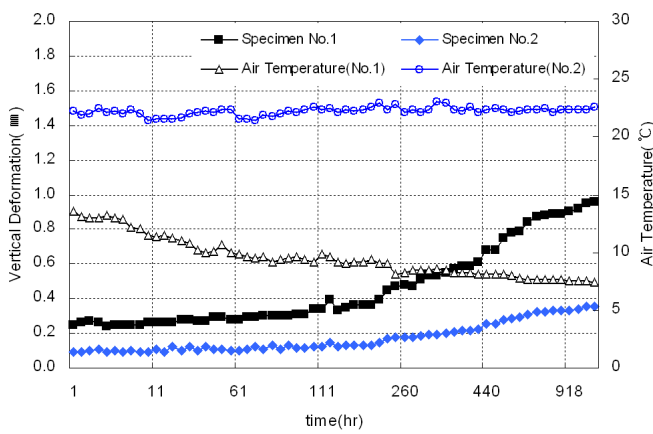

Fig. 7. Relationship between vertical deformation and temperature

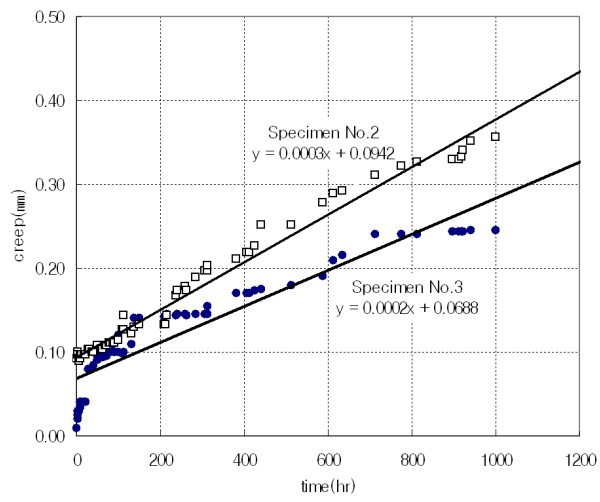

Fig. 9. Effect of shear modulus $(G)$

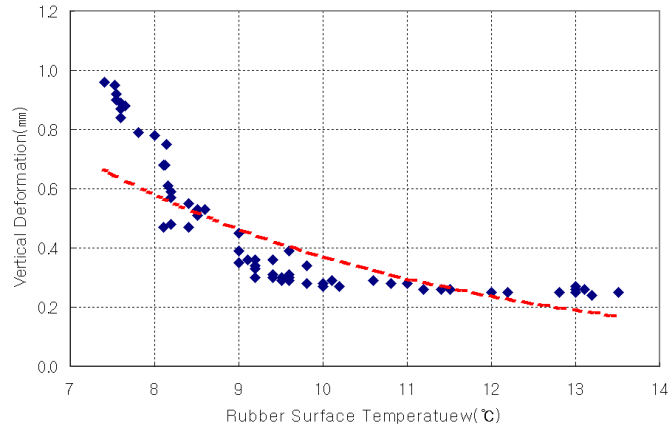

Fig. 8. Relationship between vertical deformation and temperature for fluctuation of the compressive load

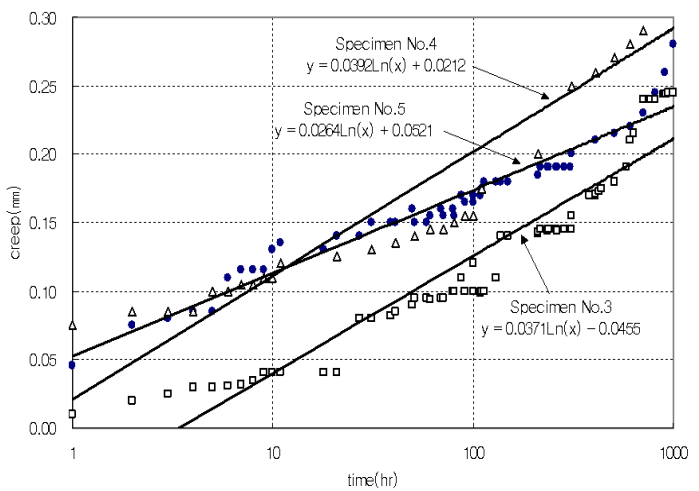

Fig. 10. Effect of primary shape factor $\left(S_{1}\right)$

Table 4. Estimated creep value $(\mathrm{mm})$

\begin{tabular}{|c|c|c|c|c|c|c|}
\hline \multicolumn{3}{|c|}{ Specimen } & $1000 \mathrm{hrs}$ & 60 yrs after & 100 yrs after & Condition \\
\hline \multirow{3}{*}{ HDRB } & \multirow{2}{*}{ No. 1 1} & Creep (mm) & 0.96 & 2.77 & 2.92 & \multirow{2}{*}{ Air temperature } \\
\cline { 2 - 6 } & \multirow{2}{*}{ No. 2 } & Strain ratio (\%) & 1.92 & 5.54 & 5.84 & \\
\cline { 3 - 6 } & & Creep (mm) & 0.36 & 1.54 & 1.62 & \\
& \multirow{2}{*}{ No. 3 3} & Creep (mm) & 0.24 & 0.54 & 0.56 & \multirow{3}{*}{ Laboratory } \\
\cline { 3 - 6 } & & Strain ratio (\%) & 0.48 & 1.08 & 1.12 & \multirow{2}{*}{$\left(23 \pm 2{ }^{\circ} \mathrm{C}\right)$} \\
\hline \multirow{2}{*}{ LRB } & \multirow{2}{*}{ No. 4 } & Creep (mm) & 0.38 & 0.98 & 1.03 & \\
\cline { 3 - 6 } & & Strain ratio (\%) & 0.44 & 1.12 & 1.18 & \\
\hline \multirow{2}{*}{ NRB } & \multirow{2}{*}{ No. 5 } & Creep(mm) & 0.28 & 1.02 & 1.08 & \\
\cline { 3 - 6 } & & Strain ratio (\%) & 0.3 & 1.10 & 1.16 & \\
\hline
\end{tabular}

HDRB test specimens No. 1, 2, and 3 are expected to deform by $0.54,1.54$, and $2.77 \mathrm{~mm}$, respectively, after 60 yrs of use under the design compression stress condition. The deformation rate of each test specimen is expected to deform from a minimum of $1.08 \%$ to a maximum of $5.54 \%$ after 60 yrs of use. Here, the creep deformation rate was calculated by dividing the estimated creep data that was based on the test results by the total thickness of the rubber layers. 


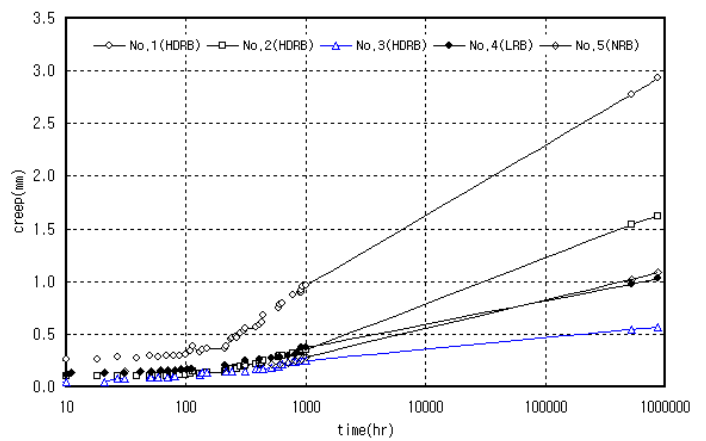

Fig. 12. Comparison of creep (mm)

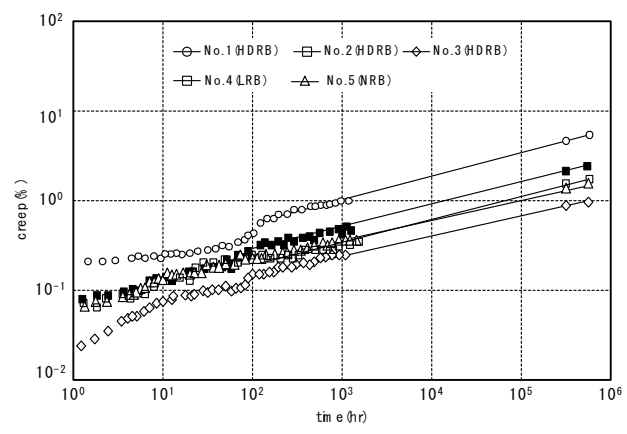

Fig. 13. Comparison of creep rate (\%)

\section{Conclusions}

We performed creep tests in order to determine the creep deformation characteristics of an LRB, HDRB, and LRB, and NRB manufactured based on seismic isolation design that is not usually considered at the design stage. The creep tests were performed for $1000 \mathrm{hr}$ on three types of laminated rubber bearing: three specimens used high damping rubber, one specimen had lead inside the laminated rubber, and one specimen was made of regular rubber. After the test, we analyzed the measurement data and creep changes according to factors such as temperature changes and the shear modulus. We then estimated the rate of change of creep deformation after 60 years of common use. Our test results are summarized as follows:

1) The analysis of the relationship between creep vertical deformation and temperature based on the laminated rubber bearing test results at $23{ }^{\circ} \mathrm{C}$ and $23 \pm 2$ shows that a higher temperature results in a lower chance of creep deformation, and a lower temperature increases the chance of creep deformation.

2) On the condition that the size and the shape factor of shape are same, then a larger shear modulus results in an increase in creep. Also, as the primary shape factor $\left(S_{1}\right)$ increases, the vertical rigidity increases and the creep amount decreases.

3) The creep deformation calculation for three types of laminated rubber bearing under compressive load for 1000 hours shows that the deformation after 60 years is 0.56 to $2.92 \mathrm{~mm}$.

4) The laminated rubber bearing used in this research was exposed to outside environmental changeable factors such as oxidation in the air, and ozone for longer period than usual period of use on the bridge system. In this regard, a long term creep test which considers outside environmental factors that could influence creep deformation should be performed.

\section{Acknowledgement}

This research was supported by Yeungnam University Research Grant in 2016.

\section{References}

[1] Itoh Yoshito, Gu Haosheng, Satoh Kazuya, Yamamoto Yoshihisa Long-term deterioration of high damping rubber bridge bearing. Doboku Gakkai Ronbunshuu A, Vol. 62, Issue 3, 2006, p. 595-607.

[2] Stevenson A. Longevity of natural rubber in structural bearing. Plastics Rubber Proceeding and Applications, Vol. 5, Issue 3, 1985.

[3] Yamamoto Sachie, Kikuchi Masaru, Ueda Masaiki, Aiken Ian D. A mechanical model for elastomeric seismic isolation bearings including the influence of axial load. Earthquake Engineering and Structural Dynamics, Vol. 38, Issue 2, 2009, p. 157-180.

[4] Ju Oh, Nok Park Kun, Hyun Cho, Jong Yun Lee Prediction about the deflection of laminate rubber bearing due to long-term creep test. Korean Society of Civil Engineering Conference and Civil Expo, 2007, p. 2488-2491. 
[5] Sae-oui P., Sirisinha C., Hatthapanit K. Effect of blend ratio on aging, oil and ozone resistance of silica-filled chloroprene rubber/natural rubber (CR/NR) blends. eXPRESS Polymer Letters, Vol. 1, Issue 1, 2007, p. 8-14.

[6] Yura J., Kumar A., Yakut A., Topkaya C., Becker E., Colligwood J. Elastomeric Bridge Bearings: Recommended Test Methods. NCHRP Report 449, 2001, p. 42-50.

[7] Derham C. J., Waller R. A. Long-term tests confirm laboratory predictions. Rubber Development, Vol. 28, Issue 1, 1975, p. 7-11.

[8] Ju Oh, Young Park Jin, Nok Park Kun, Dong Kim See, Kyu Park Sung An experimental study of the long-term creep characteristic of high damping rubber bearings. Journal of the Earthquake Engineering Society of Korea, Vol. 13, Issue 1, 2009, p. 53-60.

[9] Kunde M. C., Jangid R. S. Seismic behavior of isolated bridges: a-state-of-the-art review. Electronic Journal of Structural Engineering, Vol. 3, 2003, p. 140-170.

[10] de Raaf Michael G. P., Tait Michael J., Toopchi-Nezhad Hamid Stability of fiber-reinforced elastomeric bearings in an unbonded application. Journal of Composite Materials, Vol. 45, Issue 18, 2011, p. 1873-1884.

[11] Kumar Manish, Whittaker Andrew S., Constantinou Michael C. Experimental investigation of cavitation in elastomeric seismic isolation bearings. Engineering Structures, Vol. 101, 2015, p. 290-305.

[12] Young Chung Gil, Ho Ha Dong, Nok Park Kun, Oh Kwon Hyung Experimental study on characteristics of low hardness rubber bearing. Journal of the Earthquake Engineering Society of Korea, Vol. 6, Issue 4, 2002, p. 39-49.

[13] ISO 22762-1. Elastomeric Seismic Protection Isolation. Part 1: Test Methods. 2010.

[14] Manos G. C., Sextos A., Mitoulis S., Kourtides V., Geraki M. Tests and improvements of bridge elastomeric bearings and software development for their preliminary design. The 14th World Conference on Earthquake Engineering, 2008.

[15] ISO 22762-2. Elastomeric Seismic Protection Isolation. Part 2: Applications for Bridges. 2010.

[16] Yoon Hyejin, Cho Changbeck, Kim Youngjin, Kwahk Imjong A experimental study on the stiffness characteristics of elastomeric bearings. Journal of the Korean Society of Civil Engineers, Vol. 28, Issue 4A, 2008, p. 475-485.

[17] ISO 22762-3. Elastomeric Seismic Protection Isolation. Part 3: Applications for Buildings. 2010.

[18] Choun Young-Sun, Park Junhee, Choi In-Kil Effects of mechanical property variability in lead rubber bearings on the response of seismic isolation system for different ground motions. Nuclear Engineering and Technology, Vol. 46, Issue 5, 2014, p. 605-618.

[19] Tae Hwang Kee, Won Seo Dae, Gook Cho Sung Prediction of long term performance and creep of laminated natural rubber bearings (NRB). Journal of the Earthquake Engineering Society of Korea, Vol. 17, Issue 3, 2013, p. 117-125.

[20] Woon Choi Se, Joon Lim Hong, Jin Cho Hyun, Nok Park Kun, Ju Oh, Young Jung Hie Evaluation of factors influencing the dynamic characteristics of low hardness high damping rubber bearings. Journal of the Earthquake Engineering Society of Korea, Vol. 12, Issue 3, 2008, p. 11-20.

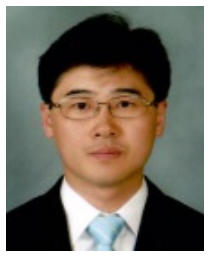

Ju Oh received Ph.D. degree in Department of Civil Engineering from University of Seoul, Seoul, Korea, in 2011. Now he works at Korea Intellectual Property Office. His current research interests include seismic and seismic isolation dynamics.

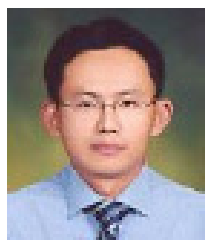

Jin Ho Kim received Ph.D. degree in Mechanical Engineering from University of California, Berkeley, USA, in 2005. Now he works as the Associate Professor at School of Mechanical Engineering, Yeungnam University, Korea. His current research interests include control, dynamics and electromagnetics. 